\title{
Where are we now? Not where we want to be. The success and failure in the implementation of Convention on Biological Diversity in Sri Lanka
}

\author{
K.A.A.N Thilakarathna ${ }^{1}$, Maj H.S.D Mendis ${ }^{2}$, Nisanka Jayarathna ${ }^{3}$ \\ ${ }^{1}$ Lecturer in Law, Institute of Human Resource Advancement, University of Colombo, Sri Lanka \\ ${ }^{2}$ Head of Department, Military Law, General Sir John Kotelawala Defence University, Sri Lanka \\ ${ }^{3}$ Senior Lecturer in Law at the Department of Legal Studies, Open University Nawala, Sri Lanka
}

\begin{abstract}
Environmental as a concern of the mankind emerged in the 1960s after the rapid infrastructural developments that were carried out after the World War II. The immediate aftermath of the war meant that countries had to work twenty-four seven to improve their man-made physical environment that was devastated by the war. However, during this period environmental concerns were not on the agenda, and it was only after sometime that humans began to be vigilant about the destruction that they have caused to the environment through their activities which was highlighted in the writing of Rachel Carson in her book titled 'The Silent Spring'. In looking at this issue from a Sri Lankan perspective, it too has suffered major setbacks regarding losing her environmental beauty and the lost of biodiversity which she is renowned for. This paper examines the implementation of the Convention on Biological Diversity which was ratified by Sri Lanka in the early 1990's and the extent to which the objectives of the convention has been achieved from a Sri Lankan perspective. This study was carried out primarily as a qualitative data, while an in-depth interview was also carried out with a high-ranking officer of the Ministry of Environment, Center for Biodiversity protection, a responsible organ for implementing the convention. The results revealed that, while laws and policies have been introduced at implementing the core elements of the convention, lack of coordination, overlapping of responsibilities, political interference and corruption has resulted in a failure of successfully implementing the convention even after nearly three decades of ratification.
\end{abstract}

Key Words: Environmental Law, Environmental Policy, Biodiversity

\section{INTRODUCTION}

64 least 40 per cent of the world's economy and 80 per A cent of the needs of the poor are derived from biological resources. In addition, the richer the diversity of life, the greater the opportunity for medical discoveries, economic development, and adaptive responses to such new challenges as climate change ${ }^{l, "}$.

The importance of these biological resources is of paramount importance for the flourishing of human beings. These resources are created by such a vast variety of plants, animals

1 OCED, The DAC Guidelines Integrating the Rio Conventions into Development Cooperation (1st, OECD Publishing, Paris 2002) 89 and other organisms which we may loosely state as the biodiversity. Hence the protection and the sustainable use of these resources or biodiversity is a sine qua non. The term 'biodiversity' is of relatively recent usage in international law. Until the 1980s, inter- national instruments tended to address 'wildlife' or 'wild fauna and flora' and focused on species and habitats ${ }^{2}$. Biodiversity refers to "the variety of different types of life found on earth. It is a measure of the variety of organisms present in different ecosystems. This can refer to genetic variation, ecosystem variation, or species variation (number of species) within an area, biome, or planet ${ }^{3}$.

With the escalating growth of the human population, the need for natural resources grew even further, and the use of those natural resources are being done in a manner that has created serious issues, including the loss of biodiversity. So many species have either become extinct or are facing serious issues with extinction. More and more species are included in the Red List of endangered species. All over the world, whether rich or poor, everyone had to face this horror. Everyone associated with this problem knew that something must be done either to totally eradicate this or to mitigate this. Against this background, the reasons for conserving nature and biodiversity are essentially threefold. First, biodiversity provides an actual and potential source of biological resources (including, for example, for use as food and feed, as well as potentially for pharmaceutical and industrial applications). Second, biodiversity contributes to the maintenance of the biosphere in a condition that supports human and other life forms. In current debates, such uses are referred to as 'ecosystem services'. Third, biodiversity is worth maintaining for non-scientific reasons of ethical, intrinsic and aesthetic value $^{4}$.

In the above said backdrop world leaders and people who are responsible for policy decisions decided that the time has come and if something is not to be done now, we may be left to regret it later as the old slogan says 'the extinction is

\footnotetext{
2 P Sands, Principles of International Environmental Law (3rd, Cambridge University Press, Cambridge 2012) 449

3 Available at http://www.biodiversitya-Z.org/content/biodiversity

4 P Sands, Principles of International Environmental Law (3rd, Cambridge University Press, Cambridge 2012) 449
} 
forever'. As a response they decided to initiate the planning for a Convention on the Biodiversity. Therefore, in 1987, the UNEP Governing Council established an Ad Hoc Working Group on Biological Diversity to investigate the desirability and possible form of an umbrella convention that would rationalize current efforts in this field and to address other areas which might fall under such a convention ${ }^{5}$.

By decision 16/42 of May 31, 1991, the Governing Council renamed this body, the Intergovernmental Negotiating Committee (INC) for a Convention on Biological Diversity. Negotiation of the Convention was done in near-record time in a mere five sessions between July 1991 and May $1992^{6}$. The Convention on Biological Diversity was adopted in May 1992 in Nairobi and was opened for signature in Rio de Janeiro in June. The Convention on Biological Diversity entered into force on 29 December 1993. There are 196 parties (195 States and the European Union) to the convention and the one major absentee is the United States of America which has signed but not yet ratified the Convention even by 2020. This convention is regarded as the main document regarding the sustainable development.

Regarding the situation in Sri Lanka, her biodiversity is considered to be the richest per unit area in the Asian region regarding mammals, reptiles, amphibians, fish and flowering plants; overtaking several mega diversity countries such as Malaysia, Indonesia and India. The global importance of the island's biodiversity has placed Sri Lanka together with the Western Ghats of India among the 34 biodiversity hotspots in the world ${ }^{7}$. This being the situation in our country, Sri Lanka signed the Convention on Biological Diversity (CBD) in June 1992, and ratified in March 1994.

\section{RESEARCH PROBLEM AND OBJECTIVE}

In the above-mentioned background, nearly after more than two and half decades from ratifying the Convention it would be of great value to re-assess the situation in Sri Lanka regarding the success and failures in the implementation process. As a country with such a great biodiversity, it is pertinent to examine the steps that have been taken to protect the biodiversity and to reduce its degradation. It would be also important to note the extent of compliance Sri Lanka has given to the Convention. Therefore, this paper endeavour to evaluate the current situation regarding the status of the laws, policies and decisions that are governing the protection of Biodiversity.

The main objective of this paper is to evaluate the current nature of the protection of the Biodiversity in Sri Lanka and to give suggestions regarding the uplifting of the current laws and policies to meet the daunting task of protecting the

5 A.A. Yusuf, 'International Law and Sustainable Development: The Biodiversity Convention. ' [1994] 2 Afr. Y.B. Int'l L 109, 112

$6 \mathrm{M}$ Chandler, 'The Biodiversity Convention: Selected Issues of Interest to the International Lawyer' [1993] 4 Colo. J. Int'l Envtl. L. \& Pol'y 141, 142-143

7 Ministry of Environment \& Renewable Energy, Sri Lanka's Fifth National Report to the Convention on Biological Diversity 2014 Biodiversity (1st, Ministry of Environment \& Renewable Energy, Battaramulla 2014) XIV
Biodiversity. From the outset it can be seen that the umbrella concept of Biodiversity may even grasp the whole of the Environmental Law into one category, meaning that all the laws that are governing the Environment may be somehow linked with the concept of Biodiversity. In such a situation this paper will try to provide possible solutions how not to come in to conflict with other laws and how to avoid the repetition of discharging of obligations (meaning if a particular objective is already carried out in accordance with a particular Act, to avoid doing the same thing under the mechanism of Biodiversity protection).

\section{METHODOLOGY}

The methodology followed in this research adopted the qualitative method and the study was conducted mainly based on a literature survey consisting of reports and documents that are written on Biodiversity Conservation and Protection. The use of journal Articles are done mostly via the internet and an in-depth interview was conducted with Director at the Center for Biodiversity protection at Battaramulla.

\section{Scope of the Convention}

The Convention on Biodiversity (CBD) is conceived as a practical tool for translating the principles of Agenda 21 into reality. The convention has an unusually long preamble which nearly runs two pages. Under Article 1 of the convention, the three main goals, 'the conservation of biological diversity, the sustainable use of its components and the fair and equitable sharing of the benefits arising out of the utilization of genetic resources' are included. The convention's governing body is the Conference of the parties (COP), consisting of all governments (and regional economic integration organizations) that have ratified the treaty. This ultimate authority reviews progress under the Convention, identifies new priorities, and sets work plans for members. The COP can also make amendments to the Convention, create expert advisory bodies, review progress reports by member nations, and collaborate with other international organizations and agreements. The CBD Secretariat based in Montreal, it operates under the United Nations Environment Programme. Its main functions are to organize meetings, draft documents, assist member governments in the implementation of the programme of work, coordinate with other international organizations, and collect and disseminate information. The Subsidiary Body on, Scientific, Technical and Technological Advice (SBSTTA) is a committee composed of experts from member governments competent in relevant fields. It plays a key role in making recommendations to the COP on scientific and technical issues

The Convention affirms the applicability of Principle 21 of the Stockholm Declaration to this context (Article 3) and provides for the State's responsibility under the Convention for activities under its control both within national jurisdiction and without (Article 4). The Convention also imposes obligations upon States in relation to in situ conservation (within a species' natural habitat) and ex situ conservation 
(Articles 8 and 9). The Convention requires Parties to promote the sustainable use of biological resources by, inter alia, integrating this objective into national decision-making, providing incentives, undertaking research and training, encouraging public education and requiring environmental impact assessments (Articles 10-14).

The Convention affirms the right of the host State to determine access to its biological resources (Article 15(1)) and creates a presumption rebuttable by the host State that access must be subject to that State's prior informed consent (Article 15(5)). It seeks to channel the benefits derived from the exploitation of biological resources to the State of origin by requiring the extracting Party to share the proceeds and results of research in a 'fair and equitable way', as appropriate, and on mutually agreed terms (Articles 15(7) and 19(2)). The Convention also provides for transfer of technology to developing countries, subject to existing patent and other intellectual property rights (Article 16).

'New and additional' financial resources are to be provided by developed countries to aid developing countries in implementing the objectives of the Convention (Article 20). The Convention does not affect the rights and obligations Parties may have pursuant to other international agreements except where fulfillment of those rights and obligations will cause 'serious damage or threat to biological diversity' (Article 22).

A Conference of the Parties (COP) is established by the Convention (Article 23), along with a Secretariat (Article 24) and a subsidiary body to provide scientific, technical and technological advice (Article 25). In addition, the Conference of the Parties set up a financial mechanism for the transfer of funds to developing countries (Article 21). The Global Environmental Facility has been acting as the interim financial mechanism of the Convention. Dispute settlement is by negotiation, mediation and, unless Parties agree otherwise, conciliation (Article 27). On ratification or at any other time, a Party may declare its acceptance of arbitration or the jurisdiction of the ICJ as a means of dispute settlement (Article 27). Amendments to the Convention or any Protocol requires approval of at least a two-thirds majority of the Parties present and voting (Article 29). Regarding most of the Articles countries are obliged to comply as appropriate and as far as possible, this goes with the principle of common but differentiated Responsibility.

To date, there are two Protocols, the Cartagena Protocol on Biosafety and the Nagoya Protocol on Access to Genetic Resources and the Fair and Equitable Sharing of Benefits Arising from their Utilization to the Convention on Biological Diversity, which have been adopted. No reservations to the Convention are permitted (Article 37) ${ }^{8}$.

8 P Sands, Documents in International Environmental Law (2nd, Cambridge University Press, Cambridge 2004) 696
Successes and Failures of the Convention at the International Level

One of the major successes of the convention has been its influence on a global dialogue of the conservation and sustainable use of the biodiversity. Presently, 195 States with differing economic, social, and cultural conditions are Parties to the Biodiversity Convention, representing all regions of the world. This is more than any other international environmental agreement other than the Framework Convention on Climate Change, and more than any international trade agreement. Most of the country parties are and have been submitting all the reports and documents which are required under the convention, and have made laws and policies in discharging their obligations towards the convention. As one commentator ${ }^{9}$ states there is plenty of potential in the convention " $[\mathrm{I}] \mathrm{n}$ essence, the Biodiversity Convention could create synergy among biodiversity-related conventions and institutions. It would ensure that the proper institutions address particular issues. It would harmonize provisions, such as reporting provisions that are common to many biodiversity-related conventions. And it would address issues not covered by existing conventions. In doing so, it would bring some degree of order to the large number of biodiversity-related conventions, reduce the redundancies in issue jurisdiction, and assure a much more efficient use of scarce funding for international environmental conventions.

However more than its successes the failures are abandon. In 2002, the parties to the 1992 Convention on Biological Diversity adopted the 2010 Biodiversity Target 'to achieve by 2010 a significant reduction of the current rate of biodiversity loss at the global, regional and national level as a contribution to poverty alleviation and to the benefit of all life on Earth'. In 2010, it was acknowledged that this target had not been met, that the state of biodiversity continued to decline and that pressures on biodiversity were increasing ${ }^{10}$. The divisiveness between developing and developed countries that fractured the negotiations continues to stifle decisions on important yet relatively simple procedural matters. The differing legal obligations imposed on Parties with different economic conditions and legal systems-by requiring Parties to implement their obligations "as far as possible and as appropriate"' also hampers progress on substantive issues ${ }^{11}$. The definition of "protected area" refers only to areas managed for conservation purposes, not sustainable use purposes, and Parties must establish protected areas to conserve biological diversity but not to sustainably use biological diversity or any of its components ${ }^{12}$.

Due to the vast scope of the Biodiversity Convention, the Parties could easily duplicate the efforts of other biodiversity-

9 C Wold, 'The Futility, Utility, and Future of the Biodiversity Convention' [1998] 9

Colo. J. Int'l Envtl. L. \& Pol'y 1,3

10 P Sands, Principles of International Environmental Law (3rd, Cambridge University Press, Cambridge 2012) 449

11 C Wold, 'The Futility, Utility, and Future of the Biodiversity Convention' [1998] 9

Colo. J. Int'l Envtl. L. \& Pol'y 1, 2

12 Ibid $\mathrm{p} 4$ 
related conventions. Just as the Biodiversity Convention includes obligations to protect species (including threatened species)," habitats, and ecosystems,' and establish protected areas for these species, habitats, and ecosystems, so too do the Convention on Wetlands of International Importance, Especially As Waterfowl Habitat (the Ramsar Convention), CITES, the Convention on the Conservation of Migratory Species of Wild Animals, among others. And due to the vast nature of the areas covered, they could discuss one issue in one $\mathrm{COP}$ and move to another topic the next year without ever taking a look back at the previous decisions and its implementation.

For example, the Parties made relatively strong efforts relating to marine and coastal biodiversity at COP2 in the Jakarta Mandate, but they barely mentioned the issue at COP3, and little action has ensued .At COP3 the Parties attempted to focus on agricultural biodiversity, that conference's issue, but many thought forests deserved more attention." The Parties accomplished little, if anything on either of the topics. Without success on any of these issues, the Parties must now turn their attention to inland freshwater ecosystems, COP4's issue. The failure of the Parties to address specific issues adequately can be attributed to the Biodiversity Convention's comprehensiveness and its vagueness ${ }^{13}$.

The CBD is an example of this myth of action. It addresses the symptoms, or indicators, of biodiversity loss, such as ecosystem degradation and species extinction, but not the underlying drivers, such as high population growth, even greater economic growth together with the misuse of fossil fuels as a primary energy source, over-consumption, growing food demand, and overwhelming poverty ${ }^{14}$. To make matters worse there is no specific Article regarding the implementation with regard to the CBD. Lakshman Guruswamy critiques the CBD: "[t]he Convention on Biological Diversity fails to address the problems it was meant to remedy. It declined to institutionalize the common responsibility of humanity to protect biodiversity, rejected the extension of state responsibility for damage to the global commons and effectively spumed, the concept of sustainable development ${ }^{15}$.

The Convention on Biological Diversity (the Biodiversity Convention) is now almost six years old as of the date of signing and more than four years old as of its entry into force.' In that time, the Biodiversity Convention has accomplished little of substance ${ }^{16}$. This may be true even after 20 from implementation.

Successes and Failures of the Convention at the Domestic Level

13 Ibid $\mathrm{p} 18$

14 R Adam, 'Missing the 2010 Biodiversity Target: A Wake-up Call for the Convention on Biodiversity?' [2010] 21 Colo. J. Int'l Envtl. L. \& Pol'y 123, 134

15 L D Guruswamy, Protection of Global Biodiversity: Converging Strategies(1st, Duke University Press, Durham, England 1998) 351

16 C Wold, 'The Futility, Utility, and Future of the Biodiversity Convention' [1998] 9 Colo. J. Int'l Envtl. L. \& Pol'y 1, 1
Sri Lanka has been a state party to the CBD from the beginning, ratifying it on 1994. In discharging her obligations towards the convention, many things have been done. In doing this, the formulation of 'Biodiversity Conservation Action Plan' (BCAP), which was undertaken in response to Article 6 of the Convention of Biological Diversity (CBD) in early 1996, was finalized in 1997. It was followed by the preparation of an 'Addendum' to the BCAP in 2003. The BCAP which was approved by the cabinet of ministers in 1998 was published in $1999^{17}$. BCAP established the post of a Secretariat to Biodiversity under the Ministry of Environment and mandated him/her to coordinate and promote the implementation of all projects and programmes under the BCAP. The BCAP brings together all activity areas that need to be addressed within a single framework, all activity areas that need to be addressed. In the BCAP, the ecosystem diversity of Sri Lanka was categorized into four broad thematic areas: (1) Forests; (2) Wetlands; (3) Coastal and Marine systems, and (4) Agricultural systems ${ }^{18}$. In addition to the 4 thematic areas, the BCAP identified specified objectives, recommended actions, and main implementing institutions for eight Cross-Cutting areas. These are: (1) Priority actions for selected bioregions, (2) Ex-situ conservation, (3) Research, (4) Education and awareness, (5) Biodiversity information, (6) Legal measures, (7) Institutional support, and (8) Valuation of biodiversity.

In 2004 Sri Lanka ratified the Cartagena Protocol on Biosafety. During 2005 and 2006, Sri Lanka carried out extensive stakeholder consultations through the National Capacity Needs Self-Assessment (NCSA) Project, in order to identify national capacity needs in implementing the Convention on Biological Diversity. Subsequently, Sri Lanka has drafted a Biosafety Regulatory Framework in 2005 and a National Policy on Bio Safety in 2011, to regulate bio technology and Genetically Modified Organisms (GMOs). These policies provide protection from the importation of GMOs, the adverse effects from bio-technology, and technology transfer issues, etc. ${ }^{19}$

Overall, there are more than 30 state institutions and 15 laws directly involved in conservation and sustainable use of biological diversity in Sri Lanka. The strategy for conservation and sustainable utilization of biodiversity evolved from various initiatives framed and formulated largely by the Ministry of Environment and Renewal Energy (MoERE), focal point for biodiversity conservation in Sri Lanka and complemented by other related Ministries/Departments and affiliated agencies dealing with Forestry, Wildlife, Environment, Agriculture, Export Agriculture, Fisheries \& Aquatic Resources, Botanic and

17 Ministry of Environment \& Renewable Energy, Sri Lanka's Fifth National Report to the Convention on Biological Diversity 2014 Biodiversity (1st, Ministry of Environment \& Renewable Energy, Battaramulla 2014) XVIII

18 Ibid

19 Dilani Hirimuthugodage , 'Biodiversity as a Cornerstone of Sustainable Development: A Sri Lankan Perspective' The Island ( Upali Newspapers (Pvt) Ltd, May 21, 2013) $<\mathrm{http}: / / \mathrm{www}$.island.lk/index.php?page_cat=article-details\&page=article-

details\&code_title=79554> accessed 29 March 2015 
Zoological Gardens etc. ${ }^{20}$ In general, the level of implementation of recommended actions of BCAP shows satisfactory (including partially achieved) results in thematic areas of Forests and Coastal and Marine systems. This achievement is over $70 \%{ }^{21}$.

Biodiversity conservation policy in Sri Lanka is based on the National Wildlife Policy (2000) and the National Forestry Policy (1995). Several other policy statements too, impinge on the biodiversity sector, including the National Environment Policy and the National Ecotourism Policy. The legal framework for biodiversity conservation rests primarily with the Fauna and Flora Protection Ordinance (FFPO) of 1937 with its later revisions, the Forest Ordinance, National Wilderness Heritage Act, National Environmental Act, Fisheries Ordinance, Coast Conservation Act and several other legislative acts ${ }^{22}$. In 2009 under the Mahinda Chinthana, a National Action Plan for Haritha Lanka Programme was launched in order to better face the environmental challenges that were prevalent in Sri Lanka.

The legislature has made some key enactments and amendments to the existing legal regime in order to fulfill the recommendations made by BCAP. Until recently, management of the forest and grassland ecosystems had been largely limited to protection, commercial extraction of timber and control of visitor activities. Stemming the rate of national forest loss is and degradation is attributed to a significant effort for better forest management which includes enforcing the ban on logging in all natural forests of the country since 1990, boundary marking of most forest and wildlife reserves to halt encroachments, halting logging of natural forests, preparation and implementation of management plans for forest and wildlife reserves (which became legal requirements under the Forest Ordinance Amendment Act No. 65 of 2009 and the Fauna and Flora Ordinance Amendment Act No 22 of 2009), and the trend to encourage community participation in forest and protected area management by both the Forest Department and the Department of Wildlife Conservation ${ }^{23}$.

With the amendment Act No 65 of 2009 which amended the, Forest Ordinance No 16 of 1907, accordingly under sections 09 and 10 of the amended Act which replaced sections 06 and 07 of the original Act, now there are six reserved areas, which are protected from human activities (named as "prohibited acts') that are likely to cause harm to the biota. And with the amendment Act No 22 of 2009 which amended the, Fauna and Flora Ordinance No 02 of 1937, under the section 40 of the Amended Act, exporting all animals other than domestic ones are prohibited and it requires a license to export any animal

20 Ministry of Environment \& Renewable Energy, Sri Lanka's Fifth National Report to the Convention on Biological Diversity 2014 Biodiversity (1st, Ministry of Environment \& Renewable Energy, Battaramulla 2014) XVIII

21 Ibid

22 N Gunatilleke Et al, 'Biodiversity of Sri Lanka Nimal' [2008] J.Natn.Sci.Foundation Sri Lanka 25, 47

23 Ministry of Environment \& Renewable Energy, Sri Lanka's Fifth National Report to the Convention on Biological Diversity 2014 Biodiversity (1st, Ministry of Environment \& Renewable Energy, Battaramulla 2014) 26 which is regarded as endangered. Most of the animals are listed as protected or non-protected in the relevant schedules of the Act.

Environmental Act No 47 of 1980 which was subsequently amended by the Act No 56 of 1988 has gazetted eight environmental Protection Areas. They are Gregory's Lake, Thalangama Lake, Bolgoda, Walauwatte-Wathurana, Muthurajawela (buffer zone), private lands within the Knuckles Conservation Forest boundary, Hantane and Maragala. Although they do not have strict legal protection, only identified development activities are allowed in them by the CEA as specified in the National Environmental Act. The CEA, however, does not have adequate mandate to monitor these areas to see that developers adhere to the conditions that need to be followed during development.

Under the recommendation 13 of the BCAP which directed to enforce, strictly the current laws against the use of explosives, illegal types of fishing gear and harvesting of juvenile and gravid lobsters in the sea has been successfully carried out under the section 27(Prohibition against the use or possession of poisonous of explosive substances) of the Fisheries and Aquatic Resources Act No 02 of 1996, where any use of poisons or explosives in fishing is prohibited. Under section 30 the relevant minister is empowered to restrict importing and exporting any species of fish including live fish or any eggs, roe or spawn or any products prepared from such fish if the minister feels the need to protect the aquatic resources of Sri Lanka, in such case a license may be required to export or import. Under the amendment Act No 35 of 2013proposals were made for the improvement of the sustainability of fish and other aquatic resources in the Fisheries Management Area $^{24}$.

Under the section 12 of the Costal Conservation Act No 57 of 1981 several costal conservation areas are established. The Coast Conservation (Amendment) Act No 49 of 2011 has increased the coastal zone to cover 100 meters of riparian land on either side of the $2 \mathrm{~km}$ water source perpendicular to a river mouth in the coastal zone. Coast Conservation Act is also strictly enforced, under section $31 \mathrm{BB}$, particularly with regard to transportation of coral to lime kilns.

Apart from the above there are other few initiatives taken as well. A draft new Act on Biosafety was prepared in 2013 and the approval procedure is in progress, and there are steps taken to introduce a policy regarding the protection of Traditional Knowledge. Also a draft Act on Plant Breeders Rights is discussed in order to share the benefits equally amongst the stakeholders.

Although these successes have occurred, much or less as a reason of the Biodiversity convention, there still remains some gray areas which have not been that successfully answered. There are so many threats that are identified with regard to the biodiversity of Sri Lanka. Sri Lanka's unique biodiversity is

24 Section 10 of the amended Act 
currently under serious threat due to increasing population pressure on ecosystems which leads to degradation, fragmentation and loss of habitats. The major causes for these effects are unplanned development activities, sedimentation due to unplanned developments, illegal encroachments, pollution, over exploitation of species, spread of alien and invasive species, climate change and natural disasters etc.

As a result of these reasons, most of the remaining habitats of endemic species in terrestrial, freshwater, coastal and marine ecosystems are under serious threat ${ }^{25}$. Habitat loss and fragmentation, degradation, spread of invasive alien species, pollution; over exploitation and climate change are now the most serious threats driving species loss in Sri Lanka. All most all the ecosystems in the country face some form of threats which ultimately result in habitat loss, degradation, change in species composition and loss of ecosystem services. Some of these may cause heavy expenditure to the government in terms of flood relief activities and to overcome health hazards etc.

One of the main problems is that there is no proper understanding of long-term ecosystem services of biodiversity outside the conservation agencies, so that only short and medium term financial benefits from bio-resources are considered. This could be due to the absence of any local initiative to carry out valuation of biodiversity taking into consideration the important ecosystem services of forests, wetlands, coastal and marine systems and agricultural systems in a holistic manner as recommended in the BCAP of 1999. Biodiversity conservation actions are adversely affected in some sectors due to inadequate coordinated functioning mechanisms, insufficient funds and human resources to implement them in a holistic manner.

In general, the level of implementation of recommended actions of BCAP shows satisfactory (including partially achieved) results in thematic areas of Forests and Coastal and Marine systems. This achievement is over $70 \%$. However, the level of implementation of recommended actions in Wetlands and Agricultural systems show less than $40 \%$ success According to the results of the analysis carried out by the Technical Working Group, the progress of implementation of 31 priority recommendations in the Addendum shows satisfactorily results only in $19.4 \%$ of the recommended actions

Even though Sri Lanka was able to establish a policy framework for bio-safety implementation, the progress remains poor. As was highlighted at a recent IPS in-house seminar, Sri Lanka does not have suitable laboratories to conduct GMO testing, which is a critical gap in implementing the policy. Further, the national BCAP (and Addendum) have not been implemented in a holistic manner. The special mechanisms required need to be identified and

25 Ministry of Environment \& Renewable Energy, Sri Lanka's Fifth National Report to the Convention on Biological Diversity 2014 Biodiversity (1st, Ministry of Environment \& Renewable Energy, Battaramulla 2014) 26 operationalized, but this is delayed due to the need for funds and other support. The coordination required for implementing the BCAP is also difficult due to the complexity arising from the vast number of institutions and laws that govern biodiversity ${ }^{26}$.

The EIA's which are required to be carried under Article 14 of the CBD is a part of our law form 1988 (with the amendment made to the CEA). Still it has no proper implications in our country, as with the case of Colombo Fort City Project where no such EIA was carried out or even if carried out not properly conducted. This perfectly illustrates the situation where even when Laws exist if taken for granted by the relevant authorities under the pressures of political whims and fancies it could result in serious harm being caused to the environment and hence to the biodiversity. It could also be seen that the offences and the punishments relating to environmental crimes are not proportionate in a sense that the punishments are not strict enough to deter the offenders from committing them. For an example any person who contravenes the section 37 of the Fauna and Flora Ordinance which related to the importing and releasing of animals is only fined 3500RS.

Another key aspect which Sri Lanka has been unable to find a proper solution is regarding the protection of Traditional Knowledge concerning biodiversity. As one commentator state $^{27}$ an area that has received less attention is Article 8(j) of CBD, which refers to traditional knowledge of a country. Sri Lanka has to give high priority to this since the country has a very rich traditional knowledge base, and has experienced several cases in the past where traditional knowledge in agriculture and medicine was lost due to the lack of rules and regulations. Indigenous knowledge and traditional crop varieties are integral features of the Sri Lankan agriculture sector, but has failed to protect this.

Since neither Environmental laws nor the laws relating to IP law which is governed by the Intellectual Property Act No 36 of 2003 gives adequate protection to Traditional Knowledge, the problem of bio-piracy which means "the unauthorized use, export, or commercial utilization of biological resources and the associated indigenous knowledge of a country are collectively known as bio-piracy"28 has become a serious threat to the country. Bio-pirates routinely exploit our indigenous knowledge and take the necessary steps to extract the medicinal properties from the relevant plants, and then patent them as their own novel product ${ }^{29}$.

Even though there are nearly eighty laws to protect biodiversity, but they need revising as many of them are outdated. A proper implementation and monitoring process

\footnotetext{
26 Dilani Hirimuthugodage, 'Biodiversity as a Cornerstone of Sustainable Development: A Sri Lankan Perspective' The Island ( Upali Newspapers (Pvt) Ltd, May 21, 2013) $<$ http://www.island.lk/index.php?page_cat=article-details\&page=article-details\&code_title=79554> accessed 29 March 2015

27 Ibid

28 G Wijesinghe, 'International Conventions and Environmental Laws in Sri Lanka' [e.g. 2005] 13 Sri Lanka J. Int'l L. 243, 251

29 Ibid
} 
needs to be in place, with closer linkages between the ministries that are responsible for sustainable development. Biodiversity policies and plans have to be integrated with agriculture and fisheries policies. As Braulio De Souza Dias, the Executive Secretary of the UN's Biological Diversity Secretariat, recently said - "Biodiversity and associated ecosystem services are the cornerstones of sustainable development. It is important to ensure that both issues are not considered in isolation". With the rapid expansion of physical infrastructure development, it is vital that biodiversity conservation is given due recognition in order to ensure that the ongoing development embodies a strong sense of sustainability. It has been 21 years since Sri Lanka ratified the Convention on Bio Diversity but it is clear that much still remains be done in terms of creating effective policy frameworks and strategies for their implementation. Concrete steps must be taken soon if Sri Lanka is to safeguard its rich bio diversity, in the midst of the rapid development taking place $^{30}$.

\section{Suggestions and Recommendations for Improving the Implementation of $C B D$}

As we have seen in the international arena, due to the vast nature or vast areas that the biodiversity covers it has been very difficult to achieve any uniformity in the law and regulations regarding the protection of biodiversity. Having a proper institutional mechanism will help to achieve a uniformity in protecting biodiversity. In Sri Lanka also, the abundance of laws and policies that directly or indirectly relate to the protection of biodiversity lacks uniformity. While some of these acts are overlapping in their mandate, others are, to some extent, in conflict as seen in the case of FFPO and the Fisheries and Aquatic Resources Act in respect of the import and export of fish and other aquatic organisms ${ }^{31}$.

There is an urgent need of reviewing all the legislation that concerns with the protection of biodiversity and to get-away with as far as possible with the conflicts amongst them. There was even a discussion on adopting a Biodiversity Act like in India. At the tenth COP held in Nagoya Japan, then minister to Environment Mr.Yapa stated that he is seriously considering the possibility or that his country is willing to adopt an Act on Biodiversity. However there hasn't been a serious discussion on this ever since.

Even though there is a separate unit regarding biodiversity in the Ministry of Environment, it lacks both the financial and man power to cover all the situations and cases, there for it would be important to have a biodiversity unit at least in few other ministries that has the duty to protect the biodiversity (like the Fisheries Ministry). The BACP needs a review as well, though an addendum was prepared in 2007 it would be imperative to set goals every 5 years so. The changings of the governments also haven't helped as it entails changes in policies as well. Sri Lanka is yet to develop measurable targets to update the BCAP to incorporate national targets in line with the Aichi Biodiversity Targets of the Strategic Plan for Biodiversity 2011-2020 and this need to be addressed as well.

The regulations to be enforced effectively, there need a strong motivation and commitment towards conservation among all stakeholders which can come effectively through increased awareness of the conservation value through field based conservation education and awareness programmes. The importance of the protecting of biodiversity must be done at the grass-root level. There is also a need of reviewing the curriculums of educational institutions that are dealing with environment, and where appropriate a focus of biodiversity and its protection must be emphasized in them as well.

We also have to amend the current IP laws, which is the most appropriate way to protect the Traditional Knowledge that we have here. And try to stop patenting of products that are derived from plants and knowledge which are inherent to us. The EIA must be made more mandatory and the approval for any project must rest on a giving of a proper EIA report.

Most importantly the politics should stay out of the arena, as it has always been a major threat to the protection of environment as a whole and the law enforcing bodies should be given the opportunity to work independently of any political pressure. And instead of boosting about reporting on the endangered species and making lists positive actions must be taken to reduce the number of them.

\section{CONCLUSION}

Does the human depend on Environment or does the environment depend on humans, the answer is most obvious. In achieving sustainable use and conserving the biological resources, we are facing a contrary ambition. In the sphere of biodiversity protection the CBD has gained acknowledgement of the fact that something needs to be that, but it stops there. Just acknowledging the fact that something must be done is not enough and the action must be put into motion, the differing obligations that the CBD casts on the developed and developing countries are hindering the hope of unanimity.

The change must happen now and all the stakeholders must take the responsibility of ensuring that future generations are to have at least the amount of resources that the current generations had at their disposal which ensures intergenerational equity. If you can't make the earth a little better place than you found it at least leave it as you found it instead of making it worse.

30 Dilani Hirimuthugodage, 'Biodiversity as a Cornerstone of Sustainable Development: A Sri Lankan Perspective' The Island ( Upali Newspapers (Pvt) Ltd, May 21, 2013)

<http://www.island.lk/index.php?page_cat=article-details\&page=article-details\&code_title=79554> accessed 29 March 2015

31 N Gunatilleke Et al, 'Biodiversity of Sri Lanka Nimal' [2008] J.Natn.Sci.Foundation Sri Lanka 25, 47 